\title{
PROGRAMA DE COMUNICAÇÃO ALTERNATIVA TÁTIL: comunicação por meio de conexões táteis
}

Flavia Daniela dos Santos Moreira

Resumo

Crianças com deficiência múltipla sensorial visual lutam diariamente para comunicar necessidades e interesses e como ainda não se expressam de modo funcional, usam modalidades comunicativas informais e idiossincráticas, chamadas de atos comunicativos. Por essa razão, esse texto tem como objetivo apresentar os benefícios do PACT - Programa de Comunicação Alternativa Tátil, desenvolvido para crianças com deficiência múltipla sensorial visual, sendo proveniente de uma pesquisa de doutorado. Por ser um estudo inédito, pretende-se divulgar o assunto entre outros professores e instigar uma reflexão sobre a utilização desse programa com outras crianças e em outros contextos, a fim de favorecer a comunicação de quem não se comunica de modo funcional e depende do tato para estabelecer conexões e se comunicar com os outros. Palavras-chave: comunicação alternativa tátil; deficiência múltipla visual; atos comunicativos.

TACTILE ALTERNATIVE COMMUNICATION PROGRAM: communication through tactile connections

\begin{abstract}
Children with multiple sensory - visual disabilities struggle daily to communicate needs and interests and, as they are not yet functional, they use informal and idiosyncratic communicative modalities, called communicative acts. For this reason, this text aims to present the benefits of PACT - Alternative Tactile Communication Program, developed for children with multiple impairment visual disabilities, coming from a doctoral research. As it is an unprecedented study, it is intended to disseminate the subject among other teachers and instigate a reflection on the use of this program with other children and in other contexts, in order to favor the communication of those who do not communicate in a functional way and depend on tact to establish connections and communicate with others.
\end{abstract}

Keywords: alternative tactile communication; multiple disabilities impairment visual; communicative acts.

PROGRAMA DE COMUNICACIÓN ALTERNATIVA TÁCTIL: comunicación a través de conexiones táctiles

\begin{abstract}
Resumen
Los niños con discapacidades sensoriales y visuales múltiples luchan diariamente para comunicar necesidades e intereses y, como aún no son funcionales, usan modalidades comunicativas informales e idiosincrásicas, llamadas actos comunicativos. Por esta razón, este texto tiene como objetivo presentar los beneficios de PACT - Programa de comunicación táctil alternativa, desarrollado para niños con discapacidades sensoriales y visuales múltiples, proveniente de una investigación doctoral. Como se trata de un estudio sin precedentes, se pretende difundir el tema entre otros docentes e instigar una reflexión sobre el uso de este programa con otros niños y en otros contextos, a fin de favorecer la comunicación de aquellos que no se comunican de manera funcional y dependen del tacto para establecer conexiones y comunicarse con otros.
\end{abstract}

Palabras clave: comunicación táctil alternativa; discapacidades sensoriales y visuales múltiples; actos comunicativos. 


\section{INTRODUÇÃO}

Crianças com deficiência múltipla constituem um grupo amplamente distinto, no que se refere às diferentes combinações de deficiências e da gravidade de cada condição. Frequentemente essas crianças são inseridas em uma categoria bastante heterogênea, representada pela combinação de diferentes deficiências, cujos efeitos podem afetar com maior ou menor intensidade sua funcionalidade ou suas habilidades em estabelecer interações sociais com outras pessoas (CARVALHO, 2000).

Por essa razão, as definições a respeito da deficiência múltipla costumam ser bastante inconsistentes e divergentes. Não há um consenso entre os pesquisadores dessa área e, consequentemente, não há uma definição única. Alguns a consideram oriunda de uma única deficiência, cuja gravidade acarreta comprometimentos em outras áreas do desenvolvimento. Outros, por sua vez, a classificam como a combinação de duas ou mais necessidades educacionais, cuja gravidade resulta em atrasos no desenvolvimento global e na capacidade adaptativa. Há também aqueles que questionam sobre a ocorrência da deficiência intelectual como fator preponderante da deficiência múltipla (OREROVE; SOBSEY, 1996; CARVALHO, 2000; ROCHA; PLETSCH, 2018).

Dependendo do conjunto de comprometimentos, pode ou não ocorrer a deficiência intelectual para que o caso em questão seja considerado como deficiência múltipla. Por outro lado, a ocorrência da deficiência intelectual define aqueles com deficiências graves, mas não requer a uma deficiência adicional (TASH, 1991).

Observa-se que quando há comprometimentos sensoriais, as denominações empregadas pela literatura internacional apontam para dois termos. O primeiro termo considerado é Multiple Disabilities Hearing Impairment (MDHI), para designar pessoas com Deficiência Múltipla Sensorial Auditiva ${ }^{1}$ no que se refere a combinação da deficiência auditiva com deficiência intelectual, física/motora ou a distúrbios globais do desenvolvimento (MAUK; MAUK, 1992). O segundo termo destacado é Multiple Disabilities Visual Impairment (MDVI), para referir-se a pessoas com Deficiência Múltipla Sensorial Visual ${ }^{2}$, as quais apresentam ou a cegueira ou a baixa visão com duas ou mais deficiências do tipo intelectual, física/motora ou distúrbios globais do desenvolvimento e deficit de comunicação (KEIL, 2003).

É importante esclarecer que a surdocegueira não é considerada como deficiência múltipla nem como deficiência múltipla sensorial, haja vista trata-se de uma condição essencialmente sensorial. Em especial às crianças com deficiência visual associada a outros comprometimentos, ressalta-se que, embora façam parte de um grupo amplamente diverso, compartilhando alguns atributos, elas se destacam em termos de suas singularidades (HORN; KANG, 2012). Muitas dessas crianças lutam diariamente para comunicar suas necessidades e interesses e, em alguns casos, como ainda não se expressam de modo funcional - formando frases ou emitindo palavras soltas - elas fazem uso de um conjunto de modalidades comunicativas informais e idiossincráticas, chamadas de atos comunicativos. Os atos comunicativos são interações precoces e elementares, manifestando-se por meio de verbalizações, vocalizações, gestos naturais, expressões faciais, protestos e meios incomuns de responder "sim" e "não". Ao longo dos anos, o valor dos atos comunicativos foi reconhecido, dada a possibilidade de direcioná-los para a aquisição de uma comunicação funcional (SIGAFOOS et al., 2000; SHUMWAY; WETHERBY, 2009).

${ }^{1}$ Termo traduzido pela autora.

${ }^{2}$ Termo traduzido pela autora. 
Além dos atos comunicativos, existem as ações comunicativas as quais, segundo Habermas (1985), dizem respeito a ações com propósito de comunicar algo a alguém. As ações comunicativas substituem as vocalizações e as verbalizações e também fazem parte do repertório comunicativo de crianças com deficiência múltipla sensorial visual.

A repetição desses atos e ações, faz com que familiares e pessoas significativas interpretem esses sinais e respondam de acordo. Ao ouvirem a criança chorando, podem interpretar como fome ou vontade de trocar a fralda. Mas nem todos compreendem adequadamente o significado desse tipo de comunicação, gerando interpretações errôneas. Por essa razão, convém utilizar recursos alternativos que apoiem o potencial comunicativo dessas crianças, considerando que boa parte das informações recebidas chegam através dos sentidos remanescentes do tato, olfato, paladar e audição. Embora haja uma variedade de recursos da comunicação alternativa, voltados para suprir ou ampliar as funções da fala, é importante selecionar aqueles que forneçam informações táteis.

Diante de tais considerações, esse texto tem como objetivo apresentar os três principais recursos táteis da comunicação alternativa, tendo como pano de fundo o PACT - Programa de Comunicação Alternativa Tátil com o propósito de instigar uma reflexão acerca do uso desses recursos no cotidiano escolar, haja vista tratar-se de um assunto ainda pouco explorado no cenário nacional.

Convém explicar que o PACT é um programa baseado na associação de gestos, objetos e símbolos táteis, cujo objetivo geral consistiu em avaliar seus benefícios e efeitos mediante a manifestação de ações comunicativas e atos comunicativos por crianças com deficiência múltipla sensorial visual. A partir desse objetivo geral, surgiram dois objetivos secundários em relação ao uso de gestos, objetos e símbolos táteis pelas crianças participantes, os quais consistiram em: a) avaliar se as crianças se apropriam do vocabulário receptivo por meio da compreensão do significado da combinação de gestos, objetos e símbolos táteis em contextos específicos, como lanche e almoço; b) analisar se elas passaram a fazer solicitações de forma autônoma, utilizado os gestos de comer e beber durante o Estudo I e usando objetos e símbolos táteis, durante o Estudo II.

\section{A COMUNICAÇÃO ALTERNATIVA TÁTIL}

O termo Comunicação Alternativa Tátil não é empregado aqui para se referir a outro tipo de comunicação alternativa, mas para se referir a um conjunto de recursos que oferecem informações por meio do tato para pessoas com um funcionamento visual tão prejudicado que lhes impossibilita interpretar imagens, palavras escritas em tinta e, em alguns casos, o braille. Nesse sentido, descreve-se a seguir, informações acerca dos três principais recursos que oferecem informações por meio do tato a pessoas que não se comunicam de modo funcional.

De um modo geral, os recursos da comunicação alternativa valorizam e incluem diversas modalidades comunicativas, tais como: os gestos manuais, expressões faciais e corporais, símbolos gráficos (bidimensionais, como as imagens e tridimensionais, como objetos de referência), recursos eletrônicos como tablets, vocalizadores e muitos outros meios que efetuam a comunicação face a face entre pessoas com dificuldades de usar a linguagem oral (NUNES, 2003). Quanto aos recursos principais táteis da comunicação alternativas, estes são representados pelos símbolos táteis, símbolos texturizados e símbolos tangíveis.

Os símbolos táteis são representações concretas, tridimensionais e servem para os mesmos propósitos que as imagens. Os símbolos táteis descritos no quadro 1 foram desenvolvidos pela Texas School for the Blind and Visually Impairment (TSBVI), localizada em Austin, Texas, para 
atender estudantes cegos e surdocegos. Suas principais características consistem em apresentar um formato, uma cor e uma textura para representar diferentes categorias de significado. Seu fundo tem uma pista perceptível, isto é, uma dica formada por objetos pequenos ou partes de objetos referentes a 12 categorias de significado, equivalentes a: tempo, eventos, locais, pessoas, emoções, objetos, comida, ações, palavras diversas, símbolos de ginásio (educação física), animais e funções matemáticas. O quadro 1 apresenta algumas dessas categorias.

Quadro 1 - Exemplos de categorias de símbolos táteis da TSBVI.

\begin{tabular}{|c|c|c|c|}
\hline CATEGORIAS & $\begin{array}{l}\text { ELEMENTOS DAS } \\
\text { CATEGORIAS }\end{array}$ & IMAGENS & DESCRIÇÃO DAS IMAGENS \\
\hline TEMPO & $\begin{array}{l}\text { Dias da semana, meses, } \\
\text { manhã, tarde ou noite, } \\
\text { hoje, amanhã, ontem, } \\
\text { minutos, segundos, horas }\end{array}$ & & $\begin{array}{l}\text { O símbolo tátil dia da semana do } \\
\text { exemplo ao lado tem formato de } \\
\text { diamante e foi feito com papel cartão } \\
\text { branco, com textura de filó vermelho } \\
\text { colado em cima desse formato. A pista } \\
\text { perceptível é um colchete aberto usado } \\
\text { geralmente em pastas ou fichários para } \\
\text { representar o dia segunda-feira escrito } \\
\text { em tinta em inglês a palavra "monday" }\end{array}$ \\
\hline EVENTOS & $\begin{array}{l}\text { Viagens, aniversário, } \\
\text { carnaval, datas } \\
\text { comemorativas (natal, } \\
\text { páscoa, etc), shows, } \\
\text { graduação, festas, } \\
\text { menstruação, piquenique, } \\
\text { olimpíadas }\end{array}$ & & $\begin{array}{l}\text { O símbolo tátil do exemplo ao lado } \\
\text { tem formato retangular, feito com } \\
\text { papel cartão laranja e textura lisa. A } \\
\text { pista perceptível é uma vela palito azul } \\
\text { para representar aniversário escrito em } \\
\text { tinta em inglês a palavra "birthday" }\end{array}$ \\
\hline LOCAIS & $\begin{array}{l}\text { Auditório, banheiro, } \\
\text { quarto, refeitório, } \\
\text { dormitório, sala de aula, } \\
\text { cozinha, hospital, } \\
\text { parquinho, piscina, banco, } \\
\text { igreja, casa, entre outros }\end{array}$ & PLATGROUND & $\begin{array}{l}\text { O símbolo tátil do exemplo ao lado } \\
\text { tem formato de quadrado feito com } \\
\text { vinil na cor preta e textura de pequenos } \\
\text { quadrados vazados. A pista perceptível } \\
\text { são pedrinhas fixadas com cola quente } \\
\text { para representar parquinho, escrito em } \\
\text { tinta em inglês a palavra "playground" }\end{array}$ \\
\hline PESSOAS & $\begin{array}{l}\text { Professor (a), inspetora, } \\
\text { pesquisadora, assistente de } \\
\text { pesquisa, entre outros }\end{array}$ & & $\begin{array}{l}\text { O símbolo tátil do exemplo ao lado } \\
\text { tem formato redondo e foi feito com } \\
\text { papel cartão com textura de papel de } \\
\text { parede texturizado branco. A pista } \\
\text { perceptível é um pequeno livro branco } \\
\text { fixado com um grampo de papel para } \\
\text { representar professor, escrito em tinta } \\
\text { em inglês a palavra "teacher" }\end{array}$ \\
\hline EMOÇÕES & $\begin{array}{l}\text { Feliz, triste, cansado, entre } \\
\text { outros }\end{array}$ & & $\begin{array}{l}\text { O símbolo tátil do exemplo ao lado } \\
\text { tem o formato de um coração e foi } \\
\text { feito com papel cartão branco e textura } \\
\text { lisa. A pista perceptível é um barbante } \\
\text { de varal branco em formato de um } \\
\text { sorriso, para representar feliz, escrito } \\
\text { em tinta em inglês a palavra "happy" }\end{array}$ \\
\hline
\end{tabular}


DOI: $10.12957 /$ teias. 2021.52640

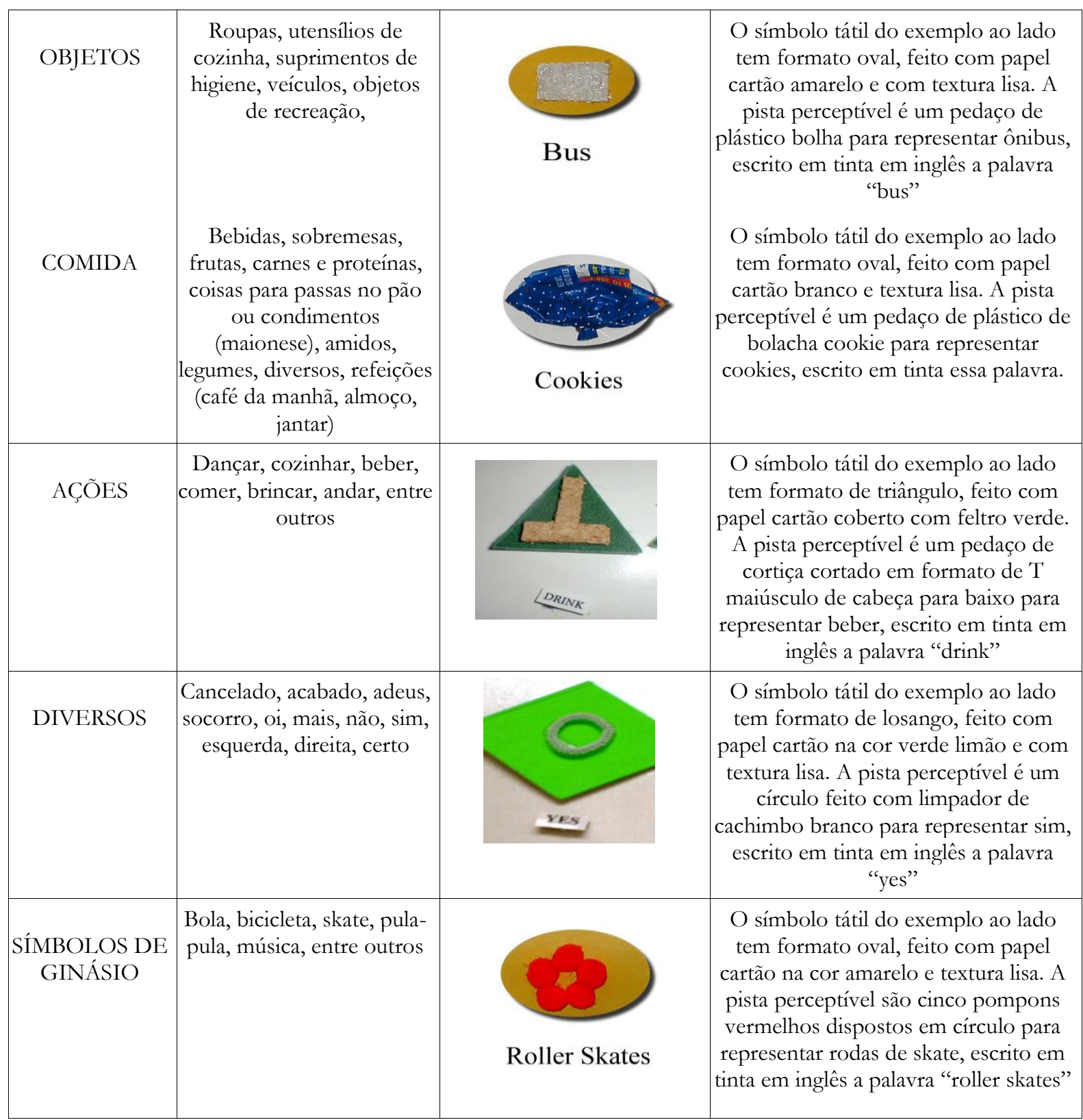

Fonte: Dados organizados, traduzidos e descritos pela autora, sendo todos os créditos atribuídos à Texas School for the Blind and Visually Impaired ${ }^{3}$ : http://www.tsbvi.edu/tactile-symbols

Os símbolos texturizados, por sua vez, são representações tatilmente salientes, tridimensionais e artificiais, com a finalidade de representar pessoas, atividades, objetos ou alimentos, para atender aos propósitos da comunicação expressiva e receptiva e devem ser individualizados para cada criança.

${ }^{3}$ Imagens com Licença Internacional Creative Commons Attribution-NonCommercial 4.0 - conteúdo disponível gratuitamente em termos legais com permissão para compartilhar e adaptar, sendo vedado seu uso para fins comerciais. Informações disponíveis em: https://creativecommons.org/licenses/by-nc/4.0/ 
Murray-Branch, Udvari-Solner e Bailey (1991) são eloquentes ao mencionar que as texturas devem ser uniformes e distintas umas das outras para evitar que sejam confundidas. Uma das grandes desvantagens desses símbolos é que não apresentam uma clara correspondência com seus referentes. Por isso, seu uso deve se basear nos interesses do aluno e, no começo, as texturas devem grandes (por exemplo: $20 \mathrm{~cm}$ x $20 \mathrm{~cm}$ ), coladas em cartões com legendas escritas em tinta e em braille e se basear nas preferências das crianças para que possam ser facilmente tocadas. Sempre que a criança tocar na textura, ela deve receber imediatamente o item preferido. Por exemplo: se a criança tocar no cartão do símbolo texturizado que representa "lanchar", ela deve imediatamente ganhar o lanche. À medida que a criança for relacionando determinada textura a um alimento, atividade ou a alguém, outras texturas podem ser oferecidas e, gradativamente, o tamanho delas pode ser reduzido (MURRAY-BRANCH; BAILEY; POFF 1998). A figura 1 mostra um exemplo de símbolo texturizado referente à fruta a banana.

Figura 1 - Cartão de símbolo texturizado.

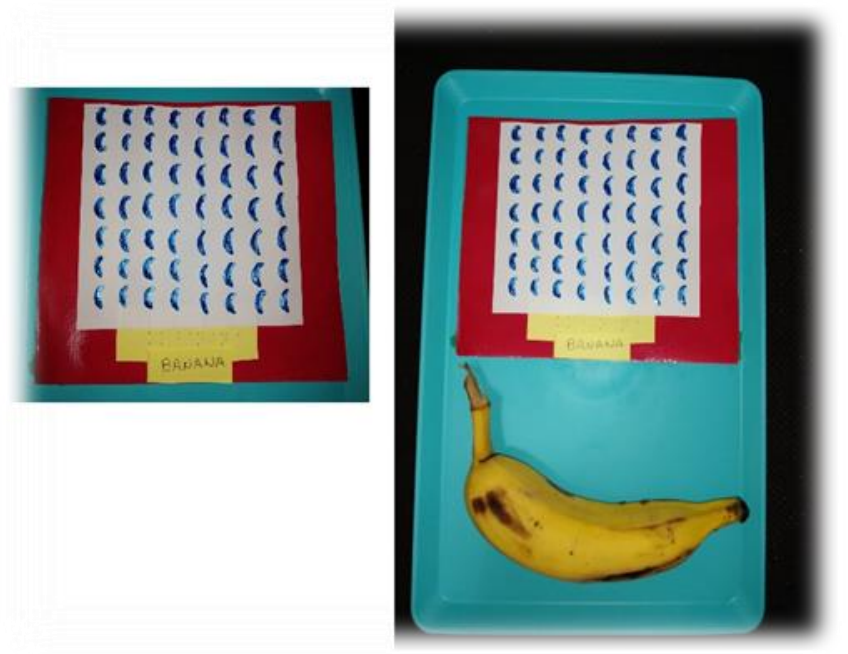

Fonte: Elaborado pela autora.

Da esquerda para a direita, a imagem da figura 1 mostra o cartão com símbolo texturizado, feito com cola relevo na cor azul, em formato de 56 meias luas. A referida textura foi feita em cima de um cartão feito com cartolina branca medindo $10 \mathrm{~cm} \times 13 \mathrm{~cm}$. Esse cartão foi colado em cima de outro cartão, feito com papel cartão vermelho plastificado medindo $13 \mathrm{~cm} \times 16 \mathrm{~cm}$, com legendas escritas em tinta e em braille a palavra "banana" em letras minúsculas. Ao lado direito tem-se esse mesmo cartão dentro de uma bandeja azul, em formato retangular, e uma banana para representar a fruta preferida de uma criança.

Os símbolos tangíveis, correspondem a objetos concretos, são facilmente manuseados e apresentam uma relação óbvia com seus referentes. Esses símbolos são usados para representar atividades, locais, eventos, conceitos ou pessoas, podendo ser usados para favorecer a comunicação receptiva e expressiva. Podem ser tridimensionais (objetos reais ou objetos parciais) e bidimensionais (imagens), podendo ser pregados em um cartão contendo legendas escritas em tinta e em braille (ROWLAND; SCHWEIGERT, 2000). A figura 2 apresenta um exemplo de símbolo tangível utilizado junto com símbolo tátil em um cartão de comunicação básica.

Figura 2 - Cartão de Comunicação Básica com símbolo tangível e símbolo tátil. 


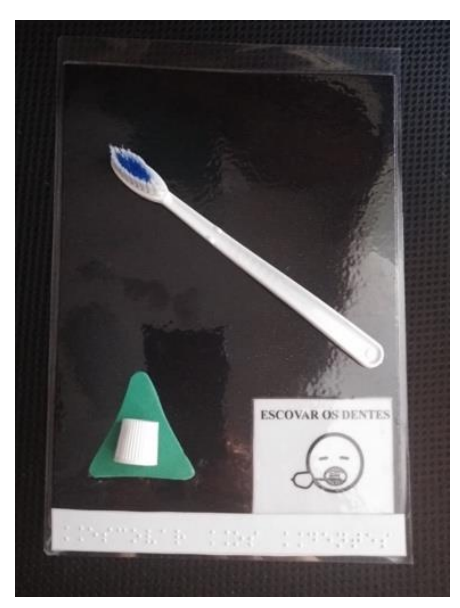

Fonte: Elaborado pela autora.

A figura 2 apresenta a imagem de um cartão de comunicação básica feito com papel cartão preto, medindo $21 \mathrm{~cm} \times 16 \mathrm{~cm}$, plastificado. Na parte inferior desse cartão tem-se uma legenda com a frase "ESCOVAR OS DENTES" escrita em braille e em letras maiúsculas. Ao lado esquerdo tem-se um símbolo tátil, categoria ação, formato triângulo, textura de papel camurça verde, com pista perceptível uma tampa de pasta de dentes branca. Ao lado direito tem-se uma legenda escrita em tinta, na cor preta, num fundo branco, a frase "ESCOVAR OS DENTES" em letras maiúsculas e o desenho de um rosto escovando os dentes. No centro desse cartão há uma escova de dentes branca, com cerdas brancas nas laterais e azuis no centro.

Os recursos da comunicação alternativa tátil não são fórmulas mágicas. Pode ser que funcionem muito bem com uma criança, assim como podem ser desconfortáveis para outras. No entanto, são possibilidades a serem pensadas para favorecer a formação de conceitos, para antecipar uma situação, para organizar a rotina escolar, para incentivar a manifestação de solicitações de forma autônoma e para valorizar a opção de escolha dessas crianças, incentivandoas a escolher algo que seja do seu interesse, usando para isso um recurso tátil.

\section{PACT: PROGRAMA DE COMUNICAÇÃO ALTERNATIVA TÁTIL}

O PACT é um programa que foi elaborado a partir de uma pesquisa de doutorado realizada com crianças com deficiência múltipla sensorial visual e que não se comunicavam de modo funcional, mas sim através de movimentos corporais, expressões faciais, gritos, agitação e outras modalidades informais e idiossincráticas. Essa pesquisa ocorreu em duas etapas chamadas de Estudo I e Estudo II.

O PACT é um programa que envolve gestos, objetos e símbolos táteis. O objetivo desse programa consistiu em ensinar três crianças com deficiência múltipla sensorial visual a se expressarem de forma autônoma usando gestos, objetos e símbolos táteis em contextos específicos. Os efeitos e benefícios do PACT foram avaliados, mediante a manifestação de atos comunicativos e ações comunicativas pelas crianças participantes. Dito em outras palavras, os benefícios e efeito do PACT foram constatados quando as crianças usaram esses recursos para fazer solicitações e/ou pedidos de modo independente. As crianças foram incentivadas a se expressarem por meio de gestos, associados a objetos dentro de contextos específicos.

Para que isso acontecesse, um prato de brinquedo foi usado para representar a ação "comer/almoço", e foi associado a um gesto natural para significar "comer". Esse gesto foi feito 
com uma das mãos aberta, dedos esticados e juntos, encostando ou tocando nos lábios. Antes de seguir para o almoço no refeitório a professora pesquisava o pratinho junto com a criança, a ajudava a fazer o gesto de "comer" e seguiam para essa atividade. Antes de servir o almoço a professora repetia esse procedimento para relembrar o que ia acontecer. Quando o almoço demorava a ser servido, a professora perguntava se a criança queria comer e elas respondiam batendo a mão nos lábios.

Algumas vezes, as crianças fizeram esse gesto sem que fossem questionadas, mostrando que tinham compreendido o significado dessa associação. Utilizou-se também um copo de brinquedo associado ao gesto natural de beber. Para fazer esse gesto a criança deveria fechar os dedos de uma das mãos e encostar o polegar nos lábios. Além desses objetos, foram utilizados outros para representar a rotina escolar compartilhada pelas crianças do estudo. A seguir, encontram-se os materiais que foram elaborados.

\section{Figura 3 - Materiais do Estudo I}

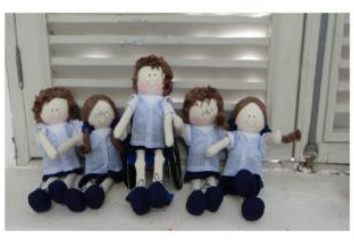

Fonte: Arquivo pessoal da pesquisadora
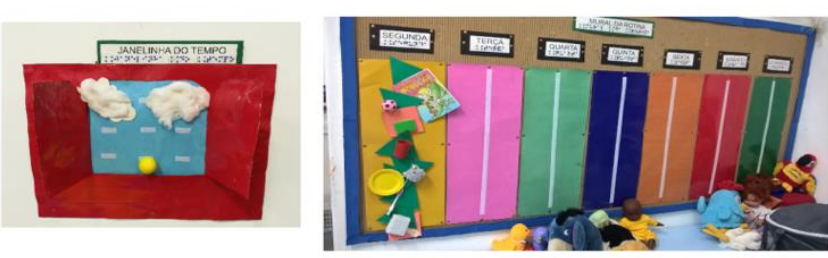

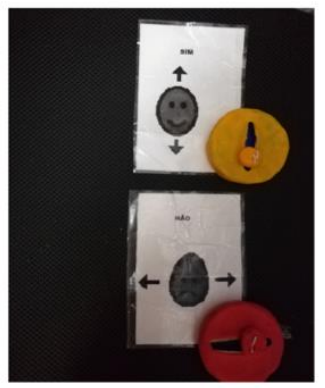

Fonte: Arquivo pessoal da autora.

Da esquerda para direita, as imagens da figura 3 mostram os seguintes materiais:

a) Bonecos da Chamada: para adquirir ou ampliar sua noção do "eu" e do "outro" as crianças pesquisavam - com ajuda da professora - as características do corpo do boneco no seu corpo e no corpo do colega; e falavam sobre quem estava presente e quem havia faltado à escola. Esses bonecos feitos com tecido de algodão branco cinco bonecos da chamada. Eram três bonecos, sendo um cego, um com baixa visão usando óculos e um cadeirante; e duas bonecas, sendo uma cega e uma com baixa visão e óculos. Vale mencionar que esses bonecos representavam as condições visuais e físicas das crianças participantes. Os bonecos vestiam jalecos com meia manga, feitos em tecido tergal xadrez azul-claro e branco. Eles usavam bermudas e sapatos com cadarço feitos em tecido de algodão na cor azul escura. Tinham cabelos curtos de lã marrom. As bonecas usavam saia e sapatos com cadarço feitos em tecido de algodão na cor azul escura. Elas tinham longos cabelos de lã marrom, divididos ao meio e com uma trança de cada lado.

b) Janelinha do Tempo: incentivar a criança a perceber se o dia estava chuvoso, ensolarado ou nublado. A janelinha do tempo foi feita em papel cartão vermelho e, no centro, foram recortadas duas partes desse papel no formato de janelas que se abriam para fora. Esse papel de cartão vermelho foi coberto com contact transparente e, na parte de trás, foi colado outro papel cartão azul-claro, também coberto com contact transparente e com pedacinhos de velcro onde as crianças pregavam nuvens feitas com algodão para representar a condição do tempo nublado e chuvoso ou o sol feito com bolinhas de isopor pintadas por elas com tinta guache amarela para representar a condição do tempo ensolarado. Os símbolos do tempo foram feitos pelas crianças com ajuda da professora. 
c) Mural da Rotina: organizar e antecipar atividades escolares a serem realizadas pelas crianças. $\mathrm{O}$ mural da rotina foi feito com tiras coloridas de papel cartão cobertas com contact transparente e com um pedaço de velcro colado no centro de cada tira para que as crianças pregassem os símbolos táteis com objetos referentes às atividades da rotina escolar. Cada dia da semana tinha uma cor: amarelo para domingo, rosa para segunda, verde-claro para terça, azul para quarta, laranja para quinta, vermelho para sexta e verde-escuro para sábado. Em cima de cada uma dessas tiras de papel cartão havia uma legenda com o nome do dia da semana escrito em tinta e em braille. A imagem mostra que da esquerda para direita tem-se o dia segunda com os símbolos táteis pregado para representar as atividades a serem realizadas naquele dia pelas crianças. A seguir tem-se os dias terça, quarta, quinta, sexta, sábado e domingo sem símbolos táteis pregados.

d) Símbolos Concretos do "sim" e do "não": auxiliar as crianças a expressarem os gestos para dizer sim e não usando os dedos, uma vez que elas ainda não faziam esses gestos com a cabeça. Os símbolos concretos do sim e do não foram feitos com tampa de maionese coberta com massa de biscuit amarela para representar "sim" e vermelha para representar "não". Cada tampa tinha um pequeno êmbolo que poderia ser movido conforme a função desejada: o êmbolo do símbolo do sim poderia ser movido para cima e para baixo para representar o balanceio de cabeça de um gesto afirmativo; o êmbolo do símbolo do não poderia ser movido para os lados direito e esquerdo para representar o balanceio de cabeça negativo.

Além destes materiais, foi elaborado um pequeno repertório de símbolos táteis referente às categorias "ação" e "local", conforme mostrado a seguir:

Figura 4 - Repertório de símbolos táteis do Estudo I.

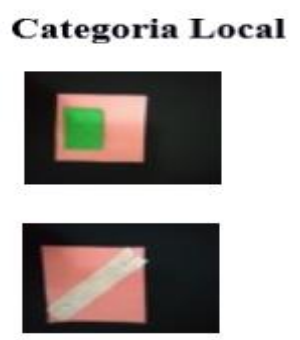

Fonte: Adaptação do material utilizado pela Texas School for the Blind and Visually Impaired (http://www.tsbvi.edu/tactilesymbols).

\section{Categoria Ação}
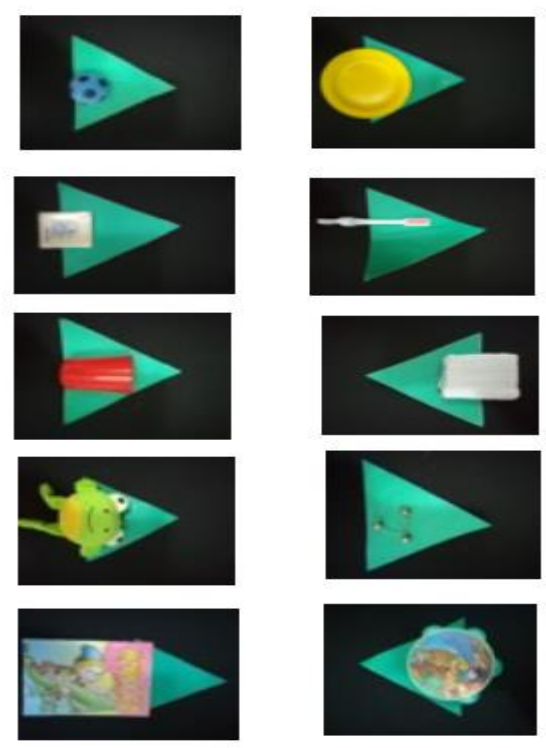
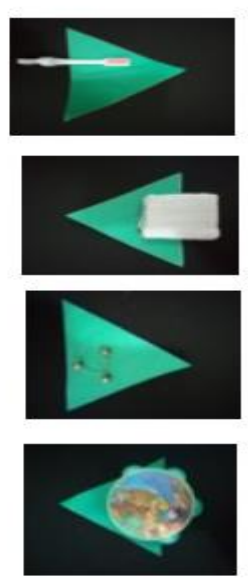

$\mathrm{Na}$ imagem mostrada pela figura 4, a categoria local encontra-se do lado esquerdo e tem formato de retângulo, feito com cartolina laranja, textura lisa e dois itens: o primeiro refere-se à sala de aula e tem pista perceptível um pedaço de tatame verde; e o segundo tem um zíper branco, referente a ficar em casa. Do lado direito encontra-se a categoria ação feita com cartolina verde, formato de triângulo, textura lisa para representar as seguintes ações: educação física (pista: bolinha 
de espuma); comer (pista: prato pequeno amarelo); lavar as mãos (pista: pequeno sabonete); escovar os dentes (pista: escova de dentes); beber (pista: copo vermelho pequeno); descansar (pista: pequena almofada); brincar/parquinho (pista: sapinho sonoro de pelúcia); música (pista: três bolinhas de guizo); ouvir história (pista: livrinho); capoeira (pista: pandeiro de brinquedo de plástico).

O Estudo II foi planejado para ocorrer em uma fase, mas como a mãe da criança participante o tirou da escola houve uma modificação e a pesquisa se desenvolveu em dois momentos: na escola e na casa de uma da criança participante. A seguir, a figura 5 apresenta os materiais elaborados durante o Estudo II.

Figura 5: Materiais elaborados no Estudo II e usado na escola.

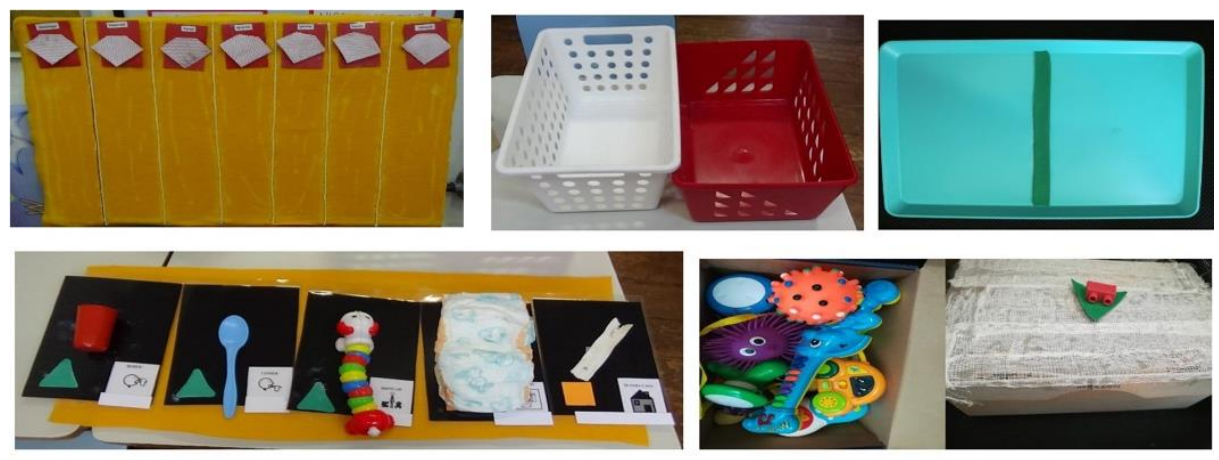

Fonte: arquivo pessoal da pesquisadora.

Da esquerda para direita, na parte superior, as imagens da figura 5 mostram o seguinte:

a) mural da rotina: $O$ mural da rotina foi feito com feltro amarelo, pregado em uma tela de pintura medindo $50 \mathrm{~cm} \times 70 \mathrm{~cm}$. Esse mural foi dividido sete vezes com pedaços de barbante branco para representar os dias da semana, os quais foram representados por símbolos táteis da categoria tempo. O objetivo desse mural consistiu em servir como uma agenda para pregar os símbolos táteis e seus respectivos objetos referentes para representar as atividades da rotina escolar de Kristian. Da esquerda para a direita, na parte superior desse mural estava pregado o cartão com o símbolo tátil dia da semana "segunda" escrito em tinta e em braille. A seguir estavam os outros cartões com seus respectivos símbolos táteis dias da semana "terça, quarta, quinta e sexta", todos escritos em tinta e em braille e separados por um pedaço de barbante branco.

b) cestas do começo e fim: O objetivo das cestas do começo e do fim consistiu em determinar o começo e o fim das atividades. Da esquerda para a direita, tem-se a cesta na cor branca e a seu lado tem-se a cesta vermelha. A cesta do começo era branca, no formato retangular, medindo $19 \mathrm{~cm} \times 28 \mathrm{~cm}$, com bolinhas em suas laterais. A cesta do fim era vermelha, no formato retangular e também medindo $19 \mathrm{~cm}$ x $28 \mathrm{~cm}$, com triângulos em suas laterais. Os símbolos táteis e seus respectivos objetos referentes eram colocados dentro da cesta do começo, depois eram retirados de lá por Kristian, com a ajuda da professora e pregados no mural da rotina. Ao final das atividades, a professora ajudava Kristian a despregar os símbolos táteis e os objetos do mural da rotina e colocá-los dentro da cesta do fim.

c) bandeja de escolhas: A bandeja de escolhas serviu para que Kristian escolhessem, com ajuda da professora, entre dois pequenos objetos aquele que ele queria para representar determinado dia da semana. Depois de escolhido, o objeto seria pregado no símbolo tátil como pista perceptível para representar determinado dia da semana. Essa bandeja media $20 \mathrm{~cm} \times 30 \mathrm{~cm}$, 
era azul e tinha uma divisória feita com emborrachado verde e os objetos eram colocados dentro dela um de cada lado.

Da esquerda para direita, na parte inferior, a imagem da figura 5 mostra o seguinte:

a) cinco cartões de comunicação básica: A prancha com os cartões de comunicação básica foi feita com feltro amarelo pregado em um pedaço de papelão medindo $30 \mathrm{~cm} \times 66 \mathrm{~cm}$ e serviu para pregar cinco cartões plastificados feitos com papel cartão preto medindo $15 \mathrm{~cm}$ x $20 \mathrm{~cm}$ cada. O objetivo desses cartões consistiu em favorecer a comunicação receptiva e expressiva de Kristian. Comunicação receptiva no sentido de pegar e pesquisar de modo exploratório o cartão, sozinho ou com a ajuda das professoras e compreender o significado dos elementos pregados no cartão. E comunicação expressiva no sentido de expressar seu interesse fazendo um pedido por meio de um dos cartões, sozinho ou com a ajuda das professoras. $\mathrm{Na}$ imagem da figura 5 , os cartões estão ordenados da seguinte forma: da esquerda para a direita tem-se o cartão "beber", em seguida o cartão "comer", depois o cartão "brincar", o cartão "banheiro" e por fim o cartão "ir embora". Cada cartão tem um objeto de referência, um símbolo tátil com pista perceptível (objeto pequeno), imagem, legenda em tinta e braille.

b) caixa de brinquedos.

Além desses materiais foi elaborado o seguinte repertório de símbolos táteis referente às categorias "tempo", para dias da semana, e "ações", conforme mostra a figura 6.

Figura 6: Repertório de símbolos táteis do Estudo II.
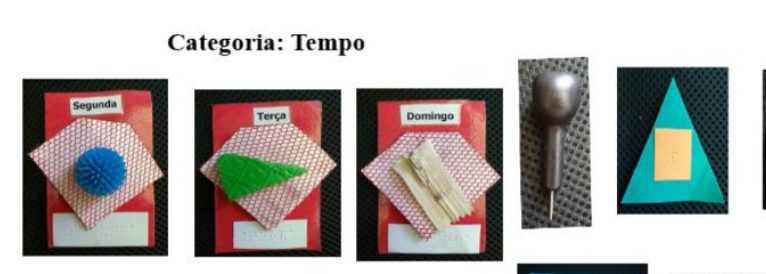

Categoria: Ação

Fonte: Adaptação do material utilizado pela Texas School for the Blind and Visually Impaired.
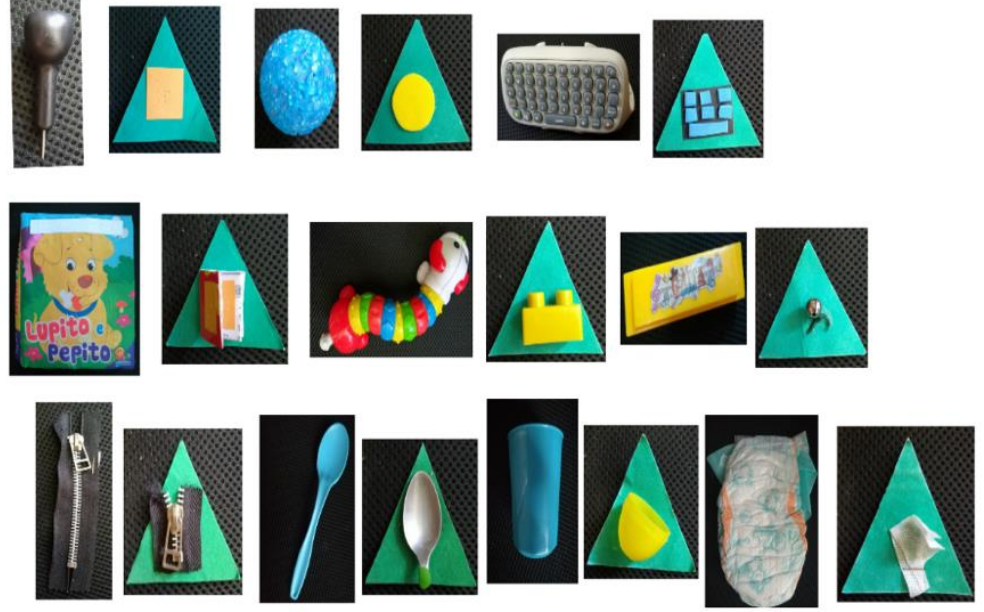

Fonte: arquivo pessoal da pesquisadora.

A imagem da figura 6 está dividida em dois blocos. Do lado esquerdo estão as categorias de tempo e do lado direito, as categorias de ação. Em relação às categorias de tempo, estas foram feitas com papel cartão branco, com textura de filó vermelho e pregada com velcro em cartões feitos com papel cartão vermelho plastificado com legendas escritas em tinta (na parte superior) e em braille (na parte inferior). As categorias de tempo mostradas são as seguintes: segunda feira (pista: bolinha de silicone espetadinha azul); terça (pista: pedaço de tatame verde); domingo (pista: pedaço de zíper branco). As pistas foram escolhidas pela criança com ajuda das professoras que colocaram dois objetos na bandeja de escolhas e pediram que a criança escolhesse um deles para representar o dia da semana.

Em relação à categoria ação, é importante ressaltar que cada símbolo tátil foi relacionado a um objeto. A descrição das imagens da figura 6 , mostra o seguinte: na primeira linha, da esquerda 
para direita tem-se um punção e seu símbolo tátil no formato de triângulo, feito com papel cartão branco, com textura de papel camurça verde e pista perceptível de uma letra "P" maiúscula escrita em braille para representar "atividades dentro da sala de aula"; em seguida tem-se uma bolinha azul, texturizada e com guizo dentro e seu símbolo tátil no formato de triângulo, feito com papel cartão branco, com textura de papel camurça verde e pista perceptível de um círculo amarelo feito com emborrachado E.V.A.; em seguida tem-se um teclado de joystick e seu símbolo tátil no formato de triângulo, feito com papel cartão branco, com textura de papel camurça verde e pista perceptível de teclas de computador para representar "aula de informática". Na segunda linha, da esquerda para direita, tem-se um livrinho de pano traduzido para o braille e seu símbolo tátil no formato de triângulo, feito com papel cartão branco, com textura de papel camurça verde e pista perceptível de um pequeno livrinho para se referir à aula de biblioteca; em seguida tem-se um chocalho de cachorrinho segmentado e seu símbolo tátil no formato de triângulo, feito com papel cartão branco, com textura de papel camurça verde e pista perceptível de uma pequena peça de lego amarelo para representar "brincar"; na sequência, há uma pequena gaita de plástico amarela e seu símbolo tátil no formato de triângulo, feito com papel cartão branco, com textura de papel camurça verde e pista perceptível de bolinha de guizo em referência à "aula de música"; a última linha da imagem mostra, da esquerda para direita, um zíper preto fechado e seu símbolo tátil no formato de triângulo, feito com papel cartão branco, com textura de papel camurça verde e pista perceptível de parte de um zíper preto representando a ação de "ficar em casa"; na sequência tem-se uma colher de plástico azul e seu símbolo tátil no formato de triângulo, feito com papel cartão branco, com textura de papel camurça verde e pista perceptível de parte de uma colher de alumínio com a parte côncava virada para cima para representar "comer"; ao seu lado tem-se um copo pequeno azul e seu símbolo tátil no formato de triângulo, feito com papel cartão branco, com textura de papel camurça verde e pista perceptível um copinho amarelo para representar "beber"; em seguida tem-se uma fralda e seu símbolo tátil no formato de triângulo, feito com papel cartão branco, com textura de papel camurça verde e pista perceptível de um pedaço de fralda representando "ir ao banheiro".

A descrição das imagens acima refere-se às categorias de símbolos táteis utilizadas no Estudo II, referentes a tempo e a ações realizadas pela criança, ou seja, referentes a sua rotina escolar.

Os materiais do Estudo II usados na casa da criança foram: a) os mesmos cartões de comunicação básica descritos anteriormente, com exceção do cartão "ir embora", pois a crianças já estava em casa; b) a mesma caixa de brinquedos usada na escola; c) uma prancha para pregar/despregas o símbolo tátil dia de atividade (atividades essa que significava brincar com os brinquedos da caixa de brinquedos); d) símbolo tátil dia de atividade. A figura 7 mostra a prancha e o símbolo dia de atividade.

Figura 7 - Prancha e símbolo tátil de atividade. 


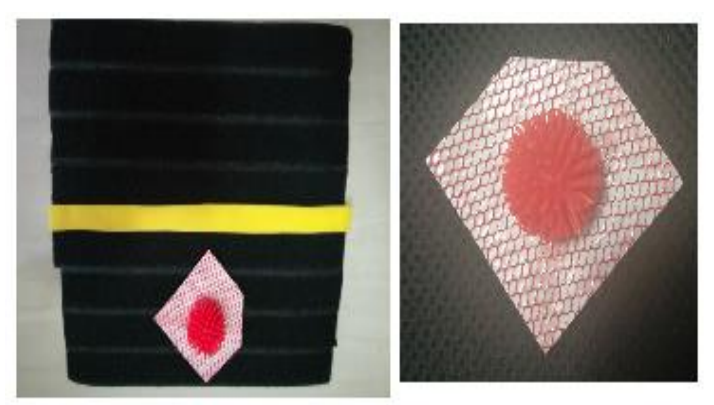

Fonte: arquivo pessoal da pesquisadora.

As etapas do PACT respeitaram a hierarquia dos símbolos, a qual considera o seguinte: primeiramente, deve-se utilizar objetos concretos e atribuir significado a eles dentro de um contexto específico. A criança deve manusear o objeto e em seguida fazer a atividade ou receber o item correspondente a ele de forma repetitiva. Quando a criança compreender o significado da ação associada ao objeto, esse objeto pode ser relacionado a um símbolo tátil que deve ser utilizado junto com o objeto de forma repetitiva. Quando a criança compreender o significado desses elementos, ela poderá utilizar somente os símbolos táteis. Essas etapas podem acontecer ou não, dependerá do tempo de entendimento de cada criança, por isso não devem ser pensadas para dar resultados em prazo definido.

Dessa forma, as etapas do PACT são as seguintes: $1^{\circ}$ ) conhecer as crianças: observá-las, elaborar um Plano de Ensino Individualizado (PEI); $2^{\circ}$ ) selecionar objetos para representar sua rotina escolar: deixar as crianças manusearem à vontade esses objetos; $3^{\circ}$ ) iniciar o uso do objetos relacionando-os às atividades: criar uma rotina repetitiva de uso; - usar cestas do começo e do fim para marcar o começo e o fim das atividades; $4^{\circ}$ ) elaborar categorias símbolos táteis para representar os dias da semana: oferecer condições para as crianças escolherem as pistas que representarão os dias; - elaborar uma categoria de símbolo tátil para representar as atividades da rotina da criança: as pitas devem ser os objetos concretos usados no início ou parte deles.

O PACT - Programa de Comunicação Alternativa Tátil - pode ser usado de forma tanto de forma individual como coletiva, desde que todas as crianças compartilhem das mesmas atividades. Seu valor social foi realçado pelas palavras da mãe de uma criança participante, que mencionou o seguinte em relação ao uso dos cartões de comunicação básica:

Eu gostei muito porque ele aprendeu a pedir a... pra comer, ele aprendeu que colher, que se refere a comer, ele sempre pede "mamãe, quero papar". A fralda ele aprendeu a falar que tá mijado. No caso era mijar, mas já foi o suficiente pra eu saber que ele quer ir no banheiro também. E brincar, né? Ele pede pra brincar, pede brinquedo. Isso ajudou muito, incentivou muito a ele falar, né? A se expressar.

Ao perguntar se ela recomendaria a outra mãe o uso desses cartões, ela respondeu: "Sim. Recomendaria sim, pra todas as mães que tem um filho como o meu, né? É que num é só... num tem só a deficiência visual, mas tem outros, outras deficiências".

O PACT é um programa inédito no cenário nacional e tem um grande valor social. Além de suas etapas excederem os muros escolares, haja vista que sua realização ocorreu dentro escola e fora dela, com a intenção de favorecer conexões por meio de recursos táteis, esse programa oferece opções de recursos a serem utilizados com crianças que ainda não se comunicam de modo funcional. 


\section{CONCLUSÕES}

Muitas crianças com deficiência múltipla sensorial visual enfrentam desafios diários para comunicar seus interesses e necessidades. A comunicação é essencial e se estabelece pela troca de informações entre duas ou mais pessoas sobre ideias, interesses e necessidades, constituindo-se como verbal, escrita ou não verbal (TRIEF, 2007; HORN; KANG, 2012).

Crianças com deficiência múltipla sensorial visual costumam se comunicar por meio de atos comunicativos e ações comunicativas que nem sempre são facilmente interpretados por todos. Nesse caso, a utilização de recursos da comunicativa tem mostrado resultados muito substanciais para favorecer ou ampliar habilidades de comunicação, linguagem e inclusive, de alfabetização, sem risco algum de impedir ou prejudicar a aquisição ou desenvolvimento da linguagem oral (NUNES, 2003).

O uso dos recursos táteis da comunicação alternativa são os mais indicados para estas crianças, por oferecerem informações táteis a quem apresenta impedimentos visuais e dificuldades de interpretar imagens, palavras escritas em tinta ou em braille. Mas, conforme sinalizado por Moreira (2020), os estudos sobre a utilização dos símbolos táteis, símbolos tangíveis e símbolos texturizados ainda são desconhecidos no cenário nacional. A mesma autora ressalta que, embora haja muitos trabalhos internacionais sobre os benefícios desses recursos, a maioria se baseia em experiências, relatos ou estudos de casos. De modo geral, precisamos de pesquisas baseadas em evidências que possam validar o uso de recursos táteis por crianças com deficiência múltipla sensorial visual.

A falta de conhecimento a respeito desse assunto foi uma das grandes barreiras enfrentadas durante a realização das etapas do PACT. Essa falta de conhecimento impediu a continuidade da referida pesquisa com as três crianças participantes e, desse modo, no Estudo II somente uma criança continuou utilizando símbolos táteis e objetos. Certamente que as habilidades aprendidas por duas dessas crianças foram esquecidas por conta do desuso.

No entanto, a originalidade e o ineditismo do PACT - Programa de Comunicação Alternativa Tátil realçam sua importância não só em termos teóricos, mas sobretudo, em relação aos benefícios que oferece a crianças sem comunicação funcional. Seus benefícios foram além de ampliar a manifestação de atos comunicativos e ações comunicativas por meio de solicitações e/ou pedidos de forma autônoma. As etapas do PACT valorizaram os pontos fortes das crianças participantes e favoreceram a formação de conceitos no que se refere a associação de um gesto, um objeto e um símbolo tátil para representar o lanche ou o almoço.

Tais aspectos realçam a necessidade de replicação do PACT, de forma contínua, tanto no ambiente escolar como na casa das crianças sob o viés de contextos e perspectivas diferenciados e que, sobretudo, favoreçam a manifestação de atos comunicativos, ações comunicativas e a formação de conceitos por outras crianças com pouca ou nenhuma linguagem oral.

\section{REFERÊNCIAS}

CARVALHO, Erenice Natália Soares de. Programa de capacitação de recursos humanos do ensino fundamental: deficiência múltipla. Vol. 1. Fascículos I - II - III. Brasília: Ministério da Educação/Secretaria de Educação Especial, 2000.

HABERMAS, Jürgen. The theory of communicative action. v. 2. 3. ed. Boston: Bacon Press Books, 1985. 
HAGOOD. Linda. A standard tactile symbol system: graphic language for individuals who are blind and unable to learn braille. Published in SEE/HEAR Newsletter TSBVI, summer 1992.

HORN, Eva M.; KANG, Jean. Supporting young children with multiple disabilities: what do we know and what do we still need to learn? Topics in Early Childhood Special Education, v. 31, n. 4, p. 241-248, 2012.

KEIL, Sue. Survey of educational provision for blind and partially sighted children in England, Scotland and Wales in 2002. British Journal of Visual Impairment, v. 21, n. 3, p. 93-97, 2003.

MAUK, Gary W.; MAUK, Pamela P. Somewhere, out there: preschool children with hearing impairment and learning disabilities. Topics in Early Childhood Special Education, v. 2, n. 2, p. 174-195, 1992.

MOREIRA, Flavia Daniela dos Santos. PACT - Programa de Comunicação Alternativa Tátil para Crianças com Deficiência Múltipla Sensorial. 2020. 219 f. Tese (Doutorado em Educação) Faculdade de Educação/ PROPED/Universidade do Estado do Rio de Janeiro, Rio de Janeiro, 2020.

MURRAY-BRANCH, Jamie; BAILEY, Brent; POFF, Lisa E. Texture as communication symbols. Special Education Programs (ED/OSERS), Washington, DC.; Indiana State Dept. of Education, Indianapolis. Div. of Special Education, 1998.

MURRAY-BRANCH, Jamie; UDVARI-SOLNER, Alice; BAILEY, Brent. Texture communication systems for individual with severe intellectual and sensory impairments. Language, Speech, and Hearing in Schools, v. 22, n. 22, p. 260-268, 1991.

NUNES, Leila Regina d'Oliveira de Paula. Linguagem e comunicação alternativa: uma introdução. In: NUNES, L. R. O. P. (Org.). Favorecendo o desenvolvimento da comunicação em crianças e jovens com necessidades educacionais especiais. Rio de Janeiro: Dunya, p. 3-13, 2003.

ORELOVE, Fred P.; SOBSEY, Dick. Educating Children with Multiple Disabilities: a transdisciplinary Approach, 3rd edition. Baltimore: Brookes, 1996.

ROCHA, Maíra Gomes de Souza da; PLETSCH, Márcia Denise. Deficiência múltipla, sistemas de apoio e processos de escolarização. Revista Horizontes - Universidade São Francisco, v. 36, n. 3, p. 99-110, set/dez 2018.

ROWLAND, Charity; SCHWEIGERT, Philip. Tangible symbol systems. 2nd edition. Design to Learn: Washigton State University, 2000.

SALLEH, Norshidah Mohamad; ALI, Manisah Mohd. Students with visual impairments and additional disabilities. International Conference on Learner Diversity. Procedia Social and Behavioral Sciences, v. 7, C, p. 714-719, 2010.

SHUMWAY, Stacy; WETHERBY, Amy M. Communicative acts of children with autism spectrum disorders in the second year of life. Journal of Speech, Language and Hearing Research: JSLHR, v. 52, n. 5, p. 1139-1156, 2009.

SIGAFOOS, Jeff et. al. Identifying potential communicative acts in children with developmental and physical disabilities. Communication Disordes Quartely, v. 21, n. 2, 77-86, 2000.

TASH (THE ASSOCIATION FOR PERSONS WITH SEVERE HANDICAPS). Definition of the People TASH Serves. In: MEYER, L. H.; PECK, C. A.; BROWN, L. Critical issues in the lives of people with severe disabilities. Baltimore: Brookes, 1991. 
TRIEF, Ellen. The use of tangible cues for children with multiple disabilities and visual impairment. Journal of Visual Impairment and Blindness, v. 101, n. 10, 2007.

Submetido em julbo de 2020

Aprovado em novembro de 2020

\section{Informações da autora}

Flavia Daniela dos Santos Moreira

Professora do Instituto Benjamin Constant/IBC

E-mail: flaviamoreira@ibc.gov.br

ORCID: https://orcid.org/0000-0003-3262-6289

Link Lattes: http://lattes.cnpq.br/5770261192834737 